\title{
Host Preference of Bactrocera cucurbitae (Diptera: Tephritidae)
}

\author{
Kiran Shahzadi', Muhammad Ahsan khan², Tayybah Gul'2, Taskeen Ahmad ${ }^{2 *}$, Farwa Aslam", Muhammad Ishfaq \\ and Iqra Aslam ${ }^{1}$ \\ ${ }^{1}$ Department of Zoology, Wildlife and Fisheries, University of Agriculture Faisalabad, Pakistan \\ ${ }^{2}$ Department of Entomology, University of Agriculture Faisalabad, Pakistan \\ *Corresponding Author: Taskeen Ahmad, Department of Entomology, University of Agriculture Faisalabad, Pakistan.
}

Received: September 30, 2019; Published: October 21, 2019

DOI: 10.31080/ASAG.2019.03.0689

\begin{abstract}
Fruit flies are polyphagous insect pest which had the prime effect on global agriculture yields and distributed extensively in temperate, tropical and subtropical regions of the world. The cucurbit fruit fly, Bactrocera cucurbitae could attack concerning sixteen different kinds of cucurbit crops. Though swarm reduced both the yield and quality of the cucurbit because the rate of attack varies among the crop. The fruit fly's relative host preference was measured on five vegetables which include bitter gourd, brinjal, cucumber and pumpkin. Vegetables were incubated and egg, larva, pupa and adult were developed in the laboratory under choice and nonchoice tests. Length and breadth of all the four developmental stages of fruit fly were measured also the duration of different stages of life cycle of fruit fly was studied. The experiment was carried out with three replications under complete randomized design. Results showed that in the non-choice test, bitter gourd was most preferred host followed by the pumpkin, brinjal, cucumber and muskmelon. The maximum egg hatched (58 per 500 grams), larva formed (51per 500g), pupa developed ( 45 per $500 \mathrm{~g}$ ) and adult developed (41 per 500g) of fruit fly. While in the case of choice test, findings showed that (67.33 per 500g) eggs, (59 per $500 \mathrm{~g}$ ) larvae, (52 per $500 \mathrm{~g}$ ) pupa, (40per 500g) adult of fruit fly were developed which showed that bitter gourd was most preferred vegetable plant host. The mean length and breadth of different developmental stages of fruit fly showed similar results. The length and breadth of male cucurbit fruit fly on bitter gourd was $(8.75 \mathrm{~mm})$ and $(12.69 \mathrm{~mm})$, whereas, the female measured $(10.2 \mathrm{~mm})$ in length and $(16.9 \mathrm{~mm})$ in breadth. Duration of different stages of life cycle of fruit fly exhibited that fruit fly (B. cucurbitae) on the bitter gourd host completed its life cycle earlier as compare to other vegetable hosts. The mean Pre-oviposition period (11.75 days) and oviposition period (12 days) while, mean mating period (0.084 hours), fecundity (249eggs/life cycle) and incubation period of eggs varied from (12.5 days) was observed of cucurbit fruit fly in bitter gourd host. Further results concluded that if a favorable host was available with breeding site then preference shifted towards the suitable host.
\end{abstract}

Keywords: Host Preference; Oviposition; Fruit Fly; Bactrocera cucurbitae; Cucurbits

\section{Introduction}

Fruit flies having several species which belong to genus Bactrocera and Tephritidae family, order Diptera and class insect. Fruit flies (Diptera: Tephritidae) are called as devastating insect pests which have a prime effect on the agriculture crops of world and marketability and value loss of agricultural products. Insect pest is responsible for low production rate and poor quality of products.
Fruit fly is one of the example of insect pest which is a serious pest of fruits and vegetables. In addition to that fruit fly is effecting the economic fatalities directly or indirectly because of the injury [1]. In Pakistan, 11 species of Bectrocera are present in different areas. B. cucurbitae, B. zonata, and B. dorsalis are most common of them. Most preferred hosts of fruit flies in Pakistan are melon (Cucumis melo), apple (Pyrus malus), mango (Mangifera indica) and bitter 
gourd (Momordica charantia) [2,3]. Polyphagous fruit fly which include cucurbit fruit fly (Bactrocera cucurbitae) is present in different areas of Pakistan. This fruit fly is a dangerous and severe insect pest in the country. Cucurbit fruit fly belonged to tropical Asia and present in many tropical countries of Asia. Cucurbit fruit fly (Bactrocera cucurbitae) is a serious pest of pumpkin, bitter gourd, sponge gourd and squash and extensive damage is caused by this pest [4]. It was concluded that fruit flies caused serious damages to crops and if necessary actions are not performed than losses can increases. Yield losses of 90 to $100 \%$ can occur due to this pest in vegetables. If certain steps were not taken than losses can reach $21 \%$ for fruits and 24\% for vegetables in Pakistan [5].

Cucurbit fruit fly (B. cucurbitae) is a limited factor for bitter gourd (Momordica charantia Linn) in earning maximum yield production and good vegetable quality. Fruit fly preferred green, tender and young vegetable for egg hatching purpose. Eggs are laid in flesh of vegetable about 2 -4 mm deep. Larvae developed inside the vegetable pulp. Larvae internally damaged the vegetables therefore, with the help of insecticides, it is problematic to control pests. For pest management, it is necessary to discover different methods for control of pest [6,7]. In various studies, host preference has been explained and host preference may shift towards the suitable host. From all animals about 25 to $40 \%$ are host specific insects. Some of the fruit flies preferred 1 to 2 host and some are host specialized and some generalist. Fruit flies decided to oviposit on vegetables depend upon the suitability of off spring performance of vegetable [8]. The present study was carried out by keeping in view the above facts to meet the following objectives. To estimate the choice and non-choice experiment of fruit fly on different vegetable crops, to determine the duration of different stages in life cycle of Bactrocera cucurbitae and to determine length and breadth of different life stages of Bactrocera cucurbita.

\section{Materials and Methods}

Host preference experiments was carried out under laboratory conditions in the Entomology lab of University of Agriculture, Faisalabad Pakistan. For this purpose, different vegetable host like cucumber, bitter gourd, brinjal and pumpkin were used which collected from the local market. Vegetables which are mature, healthy and undamaged were gathered from the market, 500g of sample retained in bags and labeled with appropriate data. Fruit fly's host preference on the different vegetables and developmental stages was evaluated in this research. By the installation of the phero- mone trap, fruit flies populations were collected which is baited with methyl eugenol, act as a sex attractant. Pheromone trap were made up of the plastic material and hung in tree. Adult fruit flies which were captured from pheromone trap identified in the entomology lab of university of Agriculture. Plastic containers were secured to prevent the other small flies' entry and emission. Simplified diets were prepared which consisted of fruit pulp (banana), yeast and egg. Banana without peel and egg were blended well in a blender and added in a plastic cup. Yeast was mixed in that mixture. From fresh vegetables, these diets varied because of increased eggs production and physical texture.

\section{Laboratory host preference studies}

Choice test

Choice experiments were organized in plastic cages in entomology lab of university of Agriculture. Vegetable host and non-host were checked. $500 \mathrm{~g}$ of sample of vegetables was placed in the cage and distance between each vegetable was $5 \mathrm{~cm}$. vegetable species (bitter gourd, cucumber, pumpkin, muskmelon and brinjal) were checked. Hundred adults of fruit flies were released into the cages for 24 hours. Bactrocera cucurbitae were fed on the mixture of diet. Vegetables were removed and placed separately in a different plastic cage for incubation. Data was recorded for egg, larval, papal and adult emergence and experiment was repeated three times.

Non-choice test

In this process, five different vegetables of $500 \mathrm{~g}$ weight were used and kept separately in five different cages. Every cage contained adult B. cucurbitae for oviposition. Fruit flies were fed on the mixture of diet. B. cucurbitae were removed from the cages and developmental period continued. To check the hatch out rate, eggs were placed into the wet blotting paper and observed under the microscope. Process proceeded as explained earlier. Data was reported according to the egg, larval, pupal and adult emergence. This experiment was repeated three times. To determine the results complete randomized design was by using the software statistx8.1. Mean were separated by the Tukey test. The experiment was repeated three times.

\section{Results}

Cucurbit fruit fly was reared from the vegetable host and results were obtained from host preference of fruit flies in table. In nonchoice experiment, egg yield of Bactrocera cucurbitae was higher on bitter gourd under lab conditions. Maximum mean number of eggs of B. cucurbitae (58) was observed in the bitter gourd followed by 
43, 42, 32 and 20 in cucumber, brinjal, pumpkin and muskmelon, respectively. Maximum mean 51 for number of larva of B. cucurbitae was witnessed in the bitter gourd followed by 34, 26, 37 and 14 in case of cucumber, brinjal, pumpkin and muskmelon, respectively. Maximum mean 45 for number of pupa of B. cucurbitae was detected in the bitter gourd followed by 31, 27, 33 and 12 in case of cucumber, brinjal, pumpkin and muskmelon, respectively. Maxi- mum mean $4.91 \mathrm{mg}$ for weight of pupa of B. cucurbitae was seen in the bitter gourd followed by $3.51 \mathrm{mg}, 4.1 \mathrm{mg}, 4.52 \mathrm{mg}$ and $2.81 \mathrm{mg}$ in case of cucumber, brinjal, pumpkin and muskmelon, respectively. Maximum mean 40 for male adult emerged from $B$. cucurbitae was noticed in the bitter gourd followed by 7, 19, 28 and 4 in case of cucumber, brinjal, pumpkin and muskmelon, respectively (Table 1).

\begin{tabular}{|l|c|c|c|c|c|c|}
\hline S. No. & $\begin{array}{c}\text { Vegetable } \\
\text { host }\end{array}$ & Eggs laid \pm SE & $\begin{array}{c}\text { Larva } \\
\text { formed } \pm \text { SE }\end{array}$ & $\begin{array}{c}\text { Pupa devel- } \\
\text { oped } \pm \text { SE }\end{array}$ & $\begin{array}{c}\text { Pupal weigh(mg) } \\
\pm \text { SE }\end{array}$ & $\begin{array}{c}\text { Adults } \\
\text { formed } \pm \text { SE }\end{array}$ \\
\hline 1. & Bittergourd & $58 \pm 0.87$ & $51 \pm 0.72$ & $45 \pm 0.63$ & $4.91 \pm 0.09$ & $41 \pm 0.60$ \\
\hline 2. & Cucumber & $43 \pm 0.61$ & $34 \pm 0.45$ & $31 \pm 0.40$ & $3.51 \pm 0.07$ & $26 \pm 0.24$ \\
\hline 3. & Brinjal & $42 \pm 0.56$ & $26 \pm 0.24$ & $22 \pm 0.21$ & $4.1 \pm 0.08$ & $16 \pm 0.17$ \\
\hline 4. & Pumpkin & $32 \pm 0.43$ & $37 \pm 0.49$ & $33 \pm 0.43$ & $4.52 \pm 0.08$ & $28 \pm 0.26$ \\
\hline 5. & Muskmelon & $20 \pm 0.19$ & $14 \pm 0.15$ & $12 \pm 0.10$ & $2.81 \pm 0.02$ & $10 \pm 0.9$ \\
\hline
\end{tabular}

Table 1: Effects of various vegetable hosts on preference and growth of fruit fly Bactrocera cucurbitae in non-choice test.

Values followed by the same letter within a column are not significantly different at the 5\% probability level.

In choice test, bitter gourd had greater egg production rate. Maximum mean (67.333) for eggs formed by the B. cucurbitae was observed in the bitter gourd followed by $29,27.667,50$ and 18.333 in case of cucumber, brinjal, pumpkin and muskmelon, respectively. Maximum mean 59 for the number of larva emerged from $\mathrm{B}$. cucurbitae was observed in the bitter gourd followed by 21,32 , 46 and 13 in case of cucumber, brinjal, pumpkin and muskmelon, respectively. Maximum mean 52 for weight of pupa of B. cucurbitae was observed in the bitter gourd followed by14, 29, 41 and 10 in case of cucumber, brinjal, pumpkin and muskmelon, respectively. Maximum mean 40 for male adult emerged from B. cucurbitae was observed in the bitter gourd followed by 7, 19, 28 and 4 in case of cucumber, brinjal, pumpkin and muskmelon, respectively (Table 2).

\begin{tabular}{|l|c|c|c|c|c|c|}
\hline S. No. & $\begin{array}{c}\text { Vegetable } \\
\text { host }\end{array}$ & Eggs laid \pm SE & $\begin{array}{c}\text { Larva formed } \\
\mathbf{\pm S E}\end{array}$ & $\begin{array}{c}\text { Pupa developed } \\
\mathbf{I S E}\end{array}$ & $\begin{array}{c}\text { Pupal weigh(mg) } \\
\pm \text { SE }\end{array}$ & $\begin{array}{c}\text { Adults formed } \\
\mathbf{S S E}\end{array}$ \\
\hline 1. & Bittergourd & $67.33 \pm 1.15$ & $59 \pm 0.48$ & $52 \pm 0.45$ & $5.5 \pm 0.91$ & $40 \pm 0.34$ \\
\hline 2. & Cucumber & $29 \pm 0.26$ & $21 \pm 0.19$ & $14 \pm 0.10$ & $4.1 \pm 0.9$ & $7 \pm 0.10$ \\
\hline 3. & Brinjal & $37.66 \pm 0.34$ & $32 \pm 0.25$ & $29 \pm 0.23$ & $4.4 \pm 0.05$ & $19 \pm 0.15$ \\
\hline 4. & Pumpkin & $50 \pm 0.46$ & $46 \pm 0.34$ & $41 \pm 0.32$ & $5 \pm 0.98$ & $28 \pm 0.19$ \\
\hline 5. & Muskmelon & $18.33 \pm 0.20$ & $13 \pm 0.10$ & $10 \pm 0.9$ & $2.9 \pm 0.02$ & $4 \pm 0.09$ \\
\hline
\end{tabular}

Table 2: Effects of various vegetable hosts on preference and growth of fruit fly Bactrocera cucurbitae in choice test. Values followed by the same letter within a column are not significantly different at the 5\% probability level.

\section{Conclusion}

The preferences of fruit flies for five hosts were tested using lab experiments. Some hosts enhanced fruit flies development more than the other tested hosts. A pronounced effect of hosts was noticed on different development and population growth statistics of individual fly. Fruit flies B. cucurbitae preferred bitter gourd, for adult feeding, oviposition and immature feeding. In non-choice experiment, egg yield of Bactrocera cucurbitae was higher on bitter gourd under lab conditions. Maximum mean number of eggs of $B$. cucurbitae (58) was observed in the bitter gourd followed by 43 , 
42, 32 and 20 in cucumber, brinjal, pumpkin and muskmelon, respectively. In choice test, bitter gourd had greater egg production rate. Maximum mean (67.333) for eggs formed by the B. cucurbitae was observed in the bitter gourd followed by 29, 27.667, 50 and 18.333 in case of cucumber, brinjal, pumpkin and muskmelon, respectively. Manzar and Srivastava [9], Lanjar., et al. [10], Rasool., et al. 2017 and Sohrab and Hasan (2018) were fairly close to this experiment. In non-choice experiment, bitter gourd was greater ranked as compare to cucumber, brinjal, pumpkin and muskmelon. Maximum mean 45 for number of pupa of B. cucurbitae was observed in the bitter gourd followed by $31,27,33$ and 12 in case of cucumber, brinjal, pumpkin and muskmelon, respectively. Similar results were found for adult emergence by Manzar and Srivastava [9], Shivay., et al. [11], Ullah., et al. [12], Lanjar., et al. [10] and Mir., et al. [13]. For choice test, greater number of pupa emerged. Maximum mean 52 for weight of pupa of B. cucurbitae was observed in the bitter gourd followed by 14, 29, 41 and 10 in case of cucumber, brinjal, pumpkin and muskmelon, respectively. This experiment results were fairly agree with Dhillon., et al. [6], Shivayya., et al. [11] and Lanjar., et al. [10]. Results was also similar to Kanika., et al. [14] and correlated to the findings of [15-17].

\section{Bibliography}

1. Sarwar MUHAMMAD. "Occurrence of Insect Pests on Guava (Psidium guajava) Tree". Pakistan Journal of Zoology 38 (2006): 197-200.

2. Sultan, M. J., et al. "Different control measures against the insect pests of bitter gourd (Momordica charantia L.)". Pakistan Journal of Biological Sciences 3 (2000): 1054-1055.

3. Ahmad B., et al. "Comparison of different methods to control fruit fly (Carpomyia vesuviana) on ber (Zizyphus mauritiana)". Pakistan Entomologist 27 (2005): 1-2.

4. Sapkota R., et al. "Damage assessment and management of cucurbit fruit flies in spring-summer squash". Journal of Entomology and Nematology 2 (2010): 7-12.

5. Sarwar M., et al. "Host preference and performance of fruit flies Bactrocera zonata (Saunders) and Bactrocera cucurbitae (Coquillett) (Diptera: Tephritidae) for various fruits and vegetables". International Journal of Scientific Research in Environmental 1 (2013): 188-194.

6. Dhillon MK., et al. "The melon fruit fly, Bactrocera cucurbitae: a review of its biology and management". Journal of Insect Science 5 (2005): 16-40.
7. Vargas RI., et al. "Effect of Physiological State on Female Melon Fly (Diptera: Tephritidae) Attraction to Host and Food Odor in the Field". Journal of Economic Entomology111 (2018): 101093.

8. Fontellas-Brandalha TML., et al. "Selection of oviposition sites by wild Anastrepha obliqua (Macquart) (Diptera: Tephritidae) based on the nutritional composition". Neotropical Entomology 33 (2004): 557-562.

9. Manzar A and JP Srivastava. "Biology of melon fruit fly, (Bactrocera cucurbitae) on bitter gourd (Momordicacharantia)". Prog. Horticulture 39 (2007): 70-73.

10. Lanjar AG., et al. "Biology and population of melon fruit fly on musk melon and Indian squash". International Journal of Farming and Allied Sciences 2 (2013): 42-47.

11. Shivay V., et al. "Biology of melon fly, Bactrocera cucurbitae on different food sources". Indian Journal of Plant Protection 35 (2007): 25-28.

12. Ullah MS., et al. "Biology and host suitability of cucurbit fruit fly, Bactrocera cucurbitae (Coq.): a comparative study on five different cucurbits". Journal of Agro-Environment Science 2 (2008): 1-6.

13. Mir H., et al. "Biology of Bactrocera Cucurbitae on cucumber". Florida Entomology 97 (2014): 753-758.

14. Kanika N., et al. "Evaluation of Host Susceptibility, Oviposion and Colour Preference of the Peach Fruit Fly, Bactrocera zonata (Saunders) (Diptera: Tephritidae)". Journal of Entomology 12 (2019): 1-08.

15. Drew RAI., et al. "Attraction of fruit flies of the genus Bactrocera to colored mimics of host fruit". Entomologia Experimentalis et Applicata 107 (2003): 39-45.

16. Brevault T and S Quilici. "Influence of habitat pattern on orientation during host fruit location in the tomato fruit fly, Neoceratitis cyanescens". Bulletin of Entomological Research 97 (2007): 637-642.

17. Mahfuza K., et al. "Comparative Host Susceptibility, Oviposition, and Colour Preference of Two Polyphagous Tephritids: Bactrocera cucurbitae (Coq.) and Bactrocera tau (Walker)". Research Journal of Agriculture and Biological Sciences 7 (2011): 343-349.

\section{Volume 3 Issue 11 November 2019 (C) All rights are reserved by Taskeen Ahmad., et al.}

